Background Neuropsychiatric symptoms of systemic lupus erythematosus (SLE) are one of the more common features and are the least understood.

Objectives To clarify the association of clinical manifestations and instrumental investigation findings in children with neurolupus.

Methods 20 children (aged 5-15 years) that met 4 or more ARA criteria of SLE were examened. Investigations included immune system changes indicating increased lupus activity, lupus anticoagulant, anticardiolipin antibodies by ELISA, electroencephalogram (EEG), in 10 patients magnetic resonance imaging (MRI).

Results The clinical manifestations of neurolupus were transient ischaemic attack (2), epilepsy (3), chorea (1), coordination disturbance (4), low extremity paresis (1). Eighteen children demonstrated psychiatric disturbances (psychosis, hysteria, fobia, anorexia, behavioural abnormalities). In all 20 children intensity of neuropsychiatric symptoms correlated with lupus activity. The most severe neuropsychiatric clinical manifestations were associated with the presence antiphospholipid antibodies. Instrumental assessment revealed pathologic abnormalities in both: children with subtle clinical symptoms and children with severe brain damage. EEG demonstrated diffuse abnormalities in 12 patients, epilepsy in 3, but not sensitive enough for diagnosis. MRI visualised diffuse and focal changes in 10 children: widening subarachnoid space and cortex atrophy.

Conclusion MRI can visualise diffuse and focal changes even in children with no history of overd symptoms of neurolupus and seems to be of real help in diagnosis. Antiphospholipid antibodies appeared to be the laboratory parameter most frequently relied apon in the diagnosis of neuropsychiatric SLE and in decision regarding treatment.

\section{FRI0118 A CLINICOPATHOLOGICAL STUDY OF TUBULOINTERSTITIAL CHANGES IN PATIENTS WITH LUPUS NEPHRITIS}

${ }^{1} S$ Mulic, ${ }^{1} \mathrm{H}$ Seleskovic, ${ }^{2} \mathrm{E}$ Cickusic, ${ }^{3} \mathrm{~S}$ Trnacevic, ${ }^{4} \mathrm{E}$ Zerem, ${ }^{2} \mathrm{Z}$ Karasalihovic. ${ }^{1}$ Rheumatology; ${ }^{2}$ Pathology, Clinical Center, Tuzla, Bosnia \& Herzegovina; ${ }^{3}$ Nephrology; ${ }^{4}$ Ultrasound

10.1136/annrheumdis-2001.153

Background The prognostic importance of renal involvement in Systemic Lupus Erythematosus (SLE) is well known. Predominant interstitial nephritis is a rare manifestation of SLE. The prognostic importance of histopathological tubulointerstitial (TIC) changes in renal tissue in patients with lupus nephritis $(\mathrm{LN})$ is very little known.

Objectives Our objectives were to more precisely determine TIC in the renal tissue and correlate these data with clinical features, daily proteinuria and 24-hour creatinine clearance in pts with LN. Our long-term goal is to identify pts during clinical quiescence who may be at high risk of developing progression to renal failure from LN.

Methods Renal biopsies from 26 pts were analysed with emphasis on TIC. At the time of biopsy all pts had defined clinical evidence of active LN. Presence and intensity of oedema, inflammatory mononuclear infiltrate, fibrosis, hyaline casts and tubular atrophy were determined. TIC were graded from 0 to 3 (absent, mild, moderate and severe). We correlated these results with clinical data of 24-hour creatinine clearance (CC) and 24hour urine total protein excretion (TP) at pre-treatment and post-treatment period.
Results Patients were divided into 4 group: first group with absent TIC (0 score) 6 pts with TP mean $2.17 \mathrm{gr} / 24 \mathrm{~h}$, CC mean $1.32 \mathrm{ml} / \mathrm{s}$; second group with mild TIC (1-5 score), 12 pts with TP mean $2.61 \mathrm{gr} / 24 \mathrm{~h}$, CC mean $0.76 \mathrm{ml} / \mathrm{s}$; third group with moderate TIC ( 6 do 10 score) 5 pts with TP mean $2.67 \mathrm{gr} /$ $24 \mathrm{~h}$, CC $0.95 \mathrm{ml} / \mathrm{s}$; forth group with severe TIC (11 to 15 score) 3 pts with TP mean 1.52, CC mean $0.37 \mathrm{ml} / \mathrm{s}$. These analyses we repeated after treatment with corticosteroids and citotoxyc drugs at period of 3 to 6 months and correlated with previous data. Significant results occurred for TP in first group $(\mathrm{p}<0.05)$ and in second group $(\mathrm{p}<0.01)$, as well as in second group for CC $(\mathrm{p}<0.05)$.

Significant improvement for both parameters occurred in group of 12 pts with mild TIC. (TP $\mathrm{p}<0.01$; CC $\mathrm{p}<0.05$ ). In group of pts with severe TIC, TP has decreased as well as CC. Conclusion TP decrease as well as increase of CC correlated well with mild degree of TIC. TIC could be prognostic predictors in LN. This has to be proved with a greater number of pts.

\section{FRI0119 HLA-DM POLYMORPHISM IN SYSTEMIC LUPUS ERYTHEMATOSOUS (SLE)}

${ }^{1} \mathrm{C}$ Da Silva Simoes, ${ }^{1} \mathrm{~J}$ Morel, ${ }^{2} \mathrm{MT}$ Salles, ${ }^{2} \mathrm{O}$ Avinens, ${ }^{1} \mathrm{~J}$ Sany, ${ }^{2} \mathrm{JF}$ Eliaou, ${ }^{1} \mathrm{~B}$ Combe. ${ }^{1}$ Rhumatologie; ${ }^{2}$ Immunologie, Hopital Lapeyronie, Montpellier, France

\subsection{6/annrheumdis-2001.154}

Background HLA-DR (DRB1*15 and DRB1*03) component is weakly associated to SLE and other genes and genetic regions are investigated in order to better characterise the genetic predisposition to the disease. DMA and DMB genes are located within the HLA class II region. The alpha beta heterodimer encoded by these genes is directly involved in the HLA class II-restricted antigen presentation pathway. Limited nucleotide polymorphism has been described in the 3rd exon of the DMA and DMB genes.

Objectives To look for an association between DM polymorphism and SLE, the DMA and DMB allele distribution was compared between patients and controls from the same geographic area.

Methods 73 SLE patients were selected according the 1997 ACR criteria. 147 unrelated control individuals were randomly selected (random controls: RC). A second group of 88 unrelated controls who were closely matched for DRB1 genotypes with patients was defined (matched controls: $\mathrm{MC}$ ) in order to determine whether the association between SLE and certain DM alleles resulted from direct influence of the DM genes or indirect influence through linkage disequilibrium with alleles at the DRB1 locus. All the individuals were typed for DR and DM by SSOs after genomic DNA extraction of peripheral mononuclear cells and PCR. The significance of differences in phenotype frequencies was determined by Fischer's exact tests with Bonferoni correction.

Results $49.3 \%$ of the patients carry either DRB1*15/16 (21.9\%) or DRB1*03 alleles (27.4\%), or both. DMA*0103, DMA*0104 and DMB*0102 were found to be more frequent in SLE patients compared to RC ( $\mathrm{p}=0.0012, \mathrm{p}=0.0012, \mathrm{p}=0.0097$, respectively). Similarly the frequency of these alleles was increased in patients compared to $\mathrm{MC}(\mathrm{p}=0.0058, \mathrm{p}=0.0013, \mathrm{p}=0.017$, respectively) suggesting a direct influence of DM genes on SLE susceptibility. This direct influence was confirmed by showing no significant difference of DM allele frequencies between RC and MC. Finally, after stratification of the patients and the MC 